\title{
An Alternative to Angle ANB in the Assessment of Sagittal Discrepancy: A Case for W angle, M-axis and G-axis based on a Secondary Analysis of Clinical Trial Data

M. J. Trenouth ${ }^{1 *}$, S. R. Desmond ${ }^{2}$

${ }^{1}$ Consultant Orthodontist (Retired), Royal Preston Hospital, Sharoe Green Lane, Preston, England.

${ }^{2}$ Formerly Hospital Practitioner in Orthodontics.

\section{Abstract}

Introduction: The objective was to test if $\mathrm{W}$ angle was a superior method of measuring skeletal change over angle ANB. The design was to re-analyse the results of a previously performed prospective, randomized controlled clinical trial with two parallel groups. The setting was the Orthodontic department, Royal Preston District General Hospital, Preston, United Kingdom.

Method: The participants were 26 patients randomly selected from a previous trial, aged 9-17 years undergoing treatment for Class II division 1 malocclusion (ANB $>5^{\circ}$, OJ $>6 \mathrm{~mm}$ ).

The intervention was two alternative designs of Twin-block appliance, allocated randomly. One with a Southend clasp on the upper and lower central incisors and one without. The appliances were identical in all other aspects.

The outcome measured was the skeletal and dental changes from lateral cephalometric radiographs before and after treatment.

Randomization was accomplished using a computer generated sequence. Allocation concealment was achieved with sequentially numbered, opaque, sealed envelopes. Blinding was applicable to outcome assessment only.

Results: Based on a power calculation for $\mathrm{W}$ angle, 26 patients were randomly selected from 41 in the original trial. 13 patients were analysed in the Southend group and 13 in the Non-Southend group. Baseline characteristics were similar between the groups and the trial status is completed. No harms were observed as a result of treatment.

There was a statistically significant change in $\mathrm{W}$ angle in the Southend group $\left(5.4^{\circ}\right)$ and the Non-Southend group $\left(2.8^{\circ}\right)$ $(p=0.000)$. This was greater than that for angle ANB in the Southend group $\left(-3.5^{\circ}\right)$ and Non-Southend group $\left(-2.6^{\circ}\right)$ $(\mathrm{p}=0.004)$.

There was a $2.6^{\circ}$ difference in treatment change between the Southend and Non-Southend groups for W angle but only $0.9^{\circ}$ for angle $\mathrm{ANB}$.

There was a total reduction to class I normative values for $\mathrm{W}$ angle $\left(54.4^{\circ}\right.$ Southend, $52.2^{\circ}$ Non-Southend group, norm 51-56 ${ }^{\circ}$. This was not so for angle ANB (3.9 ${ }^{\circ}$ Southend, $4.5^{\circ}$ Non-Southend, norm $\left.2.0-2.5^{\circ}\right)$.

Conclusions: The elimination of confounding factors that influence angle ANB especially change in incisor angulation meant that W angle demonstrated a greater differentiation of skeletal response both within and between the Southend and Non-Southend groups. M-axis and G-axis are stable with growth and unchanged by treatment.

Keywords: Twin-Block; Southend Clasp; Randomized Trial; Skeletal Response; Incisor Angulation; W Angle.

\section{*Corresponding Author:}

M. J Trenouth B.Sc., M.D.S., Ph.D., F.D.S., D.Orth., D.D.O,

Consultant Orthodontist (Retired), Royal Preston Hospital, Sharoe Green Lane, Preston, PR2 9HT, England.

Tel: (+44/1772) 717016

E-mail: michaeltrenouth@hotmail.co.uk

Received: June 16, 2015

Accepted: July 20, 2015

Published: July 23, 2015

Citation: M. J. Trenouth, S. R. Desmond (2015) An Alternative to Angle ANB in the Assessment of Sagittal Discrepancy: A Case for W Angle, Maxis and G-axis based on a Secondary Analysis of Clinical Trial Data. Int J Dentistry Oral Sci. S4:001, 1-9. doi: http://dx.doi.org/10.19070/23778075-SI04001

Copyright: M. J. Trenouth ${ }^{\circ}$ 2015. This is an open-access article distributed under the terms of the Creative Commons Attribution License, which permits unrestricted use, distribution and reproduction in any medium, provided the original author and source are credited.

\section{Introduction}

In the treatment of patients with Class II division 1 malocclusion, the overjet can be corrected by dento-alveolar retraction of the upper incisors or skeletal mandibular advancement [1]. In practice, overjet reduction involves both mechanisms and it is desirable to maximise the latter. Trenouth and Desmond [2,3] showed that during Twin-block appliance treatment, the presence of a Southend clasp not only reduced tipping of the upper and lower incisors, but also enhanced the skeletal correction.

Standard cephalometric analysis showed a statistically significant difference in upper incisor angulation $(p<0.005)$ between the Southend group $\left(-6.1^{\circ}\right)$ and the Non-Southend group $\left(-12.0^{\circ}\right)$. There was also a statistically significant difference $(\mathrm{p}<0.005)$ in lower incisor angulation between the Southend group $\left(3.0^{\circ}\right)$ and the Non-Southend group $\left(6.9^{\circ}\right)$. Of greater interest was a small but statistically significant difference in ANB $(\mathrm{p}<0.01)$ between 
the Southend group $\left(-3.5^{\circ}\right)$ and the Non-Southend group $\left(-2.6^{\circ}\right)$.

Retrospective studies have produced similar findings. Harradine and Gale [4] found a statistically significant difference in ANB reduction between a twin-block group with torquing springs $\left(-2.9^{\circ}\right)$ and one with a labial bow $\left(-1 \cdot 6^{\circ}\right)$. Parkin et al [5] also found a statistically significant difference in ANB reduction between a Twinblock with torquing springs and headgear $\left(-3.8^{\circ}\right)$ and one with a labial bow $\left(-2.0^{\circ}\right)$.

Angle ANB has become the most common method for assessing skeletal relationships since its introduction by Riedel [6] in 1952. However its validity can be questioned because it is influenced by factors other than antero-posterior skeletal relationships. Five confounding factors have been recognised which influence the value of angle ANB other than skeletal relationship which it purports to measure. First ANB is influenced by rotation of the maxilla and mandible $[7,10]$. Second angle ANB is altered by the position of point $\mathrm{N}$ in the antero-posterior plane [7-11]. Third angle ANB is influenced by the length $\mathrm{N}$ to $\mathrm{B}[9,10,12]$. Fourth angle ANB is influenced by the dental height that is the distance between point $\mathrm{A}$ to $\mathrm{B}[9,10]$. Fifth it has been shown that point A can be altered by movement of the upper incisor apex [13, 14] which can influence angle ANB. Similarly lower incisor apical movement can influence point $B$ as well as the upper influencing point A [15].

To overcome the disadvantages of angle ANB various alternatives have been proposed which in turn, introduce further problems. Jacobson [7] invented the Witts analysis but this relies on the occlusal plane as a reference which is highly variable both with growth and treatment [16-18] and identification [19, 20]. Baik and Ververidon [21] introduced the beta angle but this relies on anatomical points A and B and particularly the condylion which has low reproducibility. Neela et al [22] devised the Yen angle but since it measures the angle between SM and MG jaw rotation was not compensated for. Shetty et al [23] used Yen linea but this uses the variable occlusal plane for reference. Kumar et al [24] devised $P i$ analysis but this depends on natural head position and does not correlate with ANB, Witts or beta analysis.

Bhad et al [25] conceived the W angle which eliminates the five confounding factors associated with angle ANB. In particular, it compensates for jaw rotation and facial lengthening and is confined to the dentoalveolar area. It also relies on points S, M and G, which have clearer identification and are less subject to remodelling. Points $M$ and $G$ are true skeletal points whereas points $A$ and $B$ are really deep alveolar points. Both $G$ point and $M$ point introduced by Nanda and Merrill [26] remain stable with growth. No significant changes are found for C-axis (N-S-M) between 7-18 years [27] and $G$ axis (N-S-G) between 6-19 years [28]. Points $A$ and $\mathrm{B}$ change with growth and angle ANB reduces largely due to forward movement of point B. Most importantly W angle corresponds closely to ANB, Witts and beta angle [25, 29]. It is not influenced by the five confounding factors that affect angle ANB in particular incisor angulations.

Whilst there is no gold standard to determine skeletal change, it would seem there is reason to suppose that $\mathrm{W}$ angle is closer to the truth than angle ANB.

To date, the $\mathrm{W}$ angle seems the most valid method of measuring skeletal relationships un-influenced by confounding factors such as incisor inclination which can introduce bias. It is necessary to eliminate bias to reduce the number of variables to one in order to establish cause effect rather than statistical association. To answer the research question is $\mathrm{W}$ angle superior to angle ANB as a measure of skeletal change, the data from the previously reported trial $[2,3]$ was re-analysed using $\mathrm{W}$ angle. The $\mathrm{W}$ angle has not previously been used to evaluate the outcome of functional appliance treatment and had not been published when the trial was initially planned.

\section{Methods}

\section{Trial design}

The study was a prospective, randomized clinical trial with two parallel groups.

\section{Participants, eligibility, criteria and setting}

Consecutive patients requiring functional appliance treatment for Class II division 1 malocclusion were recruited into the study.

The following inclusion criteria were applied:

- Class II division 1 malocclusion

- Age range 9-17 years

- Overjet greater than $6 \mathrm{~mm}$

- $\quad$ ANB angle greater than $4^{\circ}$

The following exclusion criteria were applied:

- Patients with congenital syndromes

- Obvious asymmetry

- Prior appliance therapy

- Crowding requiring extractions

The setting was the Orthodontic department, Royal Preston District General Hospital, Preston, UK.

\section{Interventions}

The intervention investigated was two alternative designs of Twin-block appliance - one with a Southend clasp on the upper and lower central incisors and one without. The appliances were identical in all other aspects of their design (Figure 1).

In all cases, the three stage technique as described by Trenouth [30] was followed. The functional treatment was preceded by maxillary expansion to coordinate the dental arches and followed by a retainer with a steep anterior facing bite plane.

\section{Outcomes}

The treatment outcome was measured from lateral cephalometric radiographs taken before and after functional appliance treatment. All radiographs were taken on the same equipment. The pre and post-treatment radiographs were manually traced by one author (MJT), in the same order in which patients entered the study. The tracer was unaware of the group allocation until after completion of the tracings. 
Figure 1. Twin-block appliance (a) anterior, (b) lateral, (c) upper occlusal and (d) lower occlusal views.
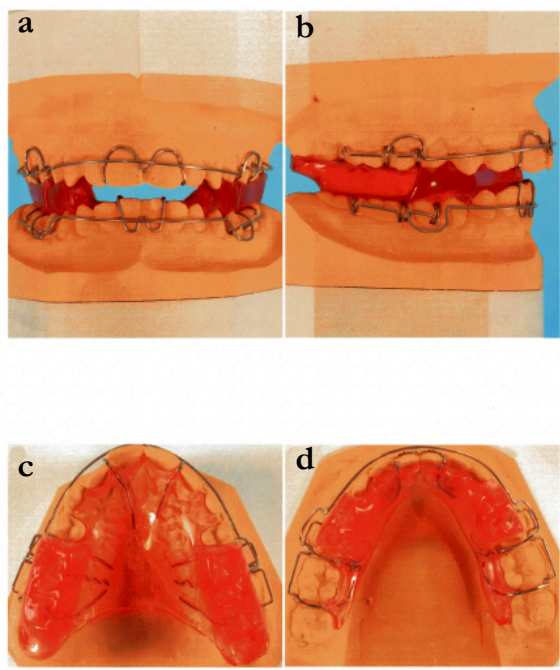

The following four points were located:

1. N-nasion, the most anterior point on the frontonasal suture.

2. S-Sella, the centre of the sellaturcica.

3. M-the mid-point of the pre-maxilla, centre of the largest circle that is tangent to the superior, anterior and palatal surfaces of the maxilla.

4. G-the centre of the largest circle that is tangent to the internal inferior, anterior and posterior surfaces of the mandibular symphysis.

Both $\mathrm{M}$ and $\mathrm{G}$ points were located using a specifically designed template composed of a number of concentric circles whose diameter increased by $1 \mathrm{~mm}$ increments. The circle of best fit to the three surfaces was determined and its centre marked.

Five lines were defined, N-S, S-M, S-G, M-G, and perpendicular from $\mathrm{M}$ to $\mathrm{S}-\mathrm{G}$.

The following three angles were measured:

1. The C-axis, angle N-S-M

2. The G-axis, angle N-S-G

3. The $\mathrm{W}$ angle, the angle between the perpendicular from point $\mathrm{M}$ to the $\mathrm{S}-\mathrm{G}$ line and the $\mathrm{M}-\mathrm{G}$ line (Figure 2).
Early in the study the age range was extended to recruit a greater number of patients more rapidly. Although it is commonly perceived that the degree of maturity influences the skeletal response recent prospective studies have found that stage of maturity of the cervical spine did not influence outcome [31, 32].

\section{Sample size calculation}

The calculation of sample sizes was based on the primary outcome of $\mathrm{W}$ angle.

The sample size was estimated to be 26 using a power calculation. This was based on an $80 \%$ power with an alpha of 0.01 , a $5^{\circ}$ difference between the means for $\mathrm{W}$ angle (Class I range 51-56 [25]) with standard deviation of $2.5^{\circ}$ (average reported by Bhad et al [25]).

\section{Interim analyses and stopping rules}

Not applicable.

\section{Randomization}

The random sequence was computer generated using the internet site www.randomization.com

Figure 2. Cephalometric points, lines and angles.

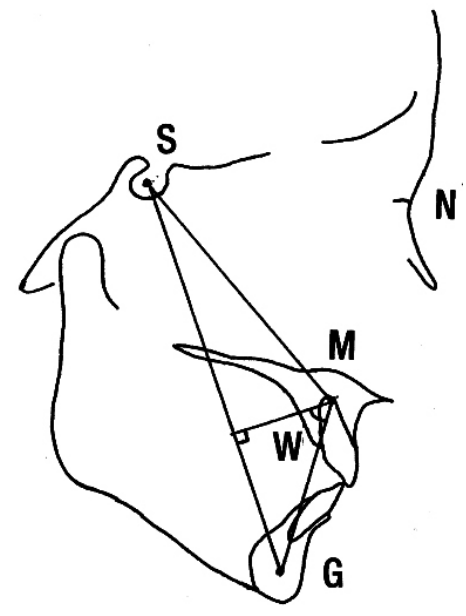


This was performed in blocks of six to ensure equal numbers in each group. Allocation concealment was with consecutively numbered opaque envelopes, which were only opened when the participant had consented to take part in the trial.

Cards were inserted in consecutively number envelopes. The cards were labelled Southend or Non-Southend, according to which design of Twin-block appliance was selected. The cards were allocated to the envelope number according to the randomization plan, which was generated from the internet site.

\section{Blinding}

Manual allocation was performed using sealed envelopes to blind the operator during enrolment of patients to the study. After enrolment blinding of the patient and operator to group allocation was not possible. A standard laboratory design sheet was produced for each alternative Twin-block appliance, to refer to in order to achieve total consistency. All appliances were constructed in the same on site laboratory. All cases were treated by one of two operators (MJT or SRD).

\section{Statistical Methods}

The data were found to be normally distributed. The mean and 95\% confidence intervals were reported.

A paired t-test was used to detect statistically significant differences before and after treatment. An un-paired t-test was used to detect any differences in treatment change between the Southend and Non-Southend groups. Statistical significant was set at $\mathrm{p}>$ 0.05 .

\section{Error Analysis}

An error assessment was performed by retracing 30 of the original 82 cephalometric radiographs selected using random number tables.

The systematic error was determined by calculating the mean of the differences between the first and second tracings (MD) [33]. The 95\% confidence intervals were also calculated. This contained zero indicating any systematic bias was not statistically significant (Table 1).

The maximum error (ME) was calculated from the intra-subject standard deviation [33]. When the standard deviations for each subject were plotted against their mean values for each of the seven variables, no significant relationships were found, nor was there any systematic bias. This indicated that the measurement error did not increase with the measurements increasing magnitude. The mean difference between repeat readings (MD) was less than the maximum error in all cases indicating an acceptable level of random error (Table 1).

\section{Ethics}

Ethical approval was granted by the Preston Chorley and South Ribble Research Ethics Committee (Ref No’s 2002. 12.11; July 2003). An International Standard Randomized Controlled Trial Number was allocated, which can be accessed at www.controlledtrials.com/ISRCTN45965219.

Informed consent was obtained prior to enrolment into the clinical trial. This involved a verbal explanation with written instruction sheet and consent form, signed by the patient.

\section{Results}

\section{Participant Flow}

The flow of participants through each stage of the study is shown in the CONSORT flow chart (Figure 3). Fifty-two patients were enrolled into the study and 26 allocated to each group. No patients refused to enter the study. In the Southend group, five patients discontinued treatment. One successfully completed treatment, but was transferred to another hospital and no final cephalometric radiograph was obtained. In the Non-Southend group, four patients discontinued treatment. One successfully completed treatment but no final cephalometric radiograph was taken due to an administrative error. The overall loss to follow-up rate was therefore $21.2 \%$ (11 out of 52 ) for patients who failed to complete the study. The failure to complete Twin-block appliance treatment was $17.3 \%$ (9 out of 52 ).

Based on the power calculation for $\mathrm{W}$ angle 26 of the original 41 patients were selected at random and re-analysed.

\section{Baseline data}

The Southend group was compared with the Non-Southend group, for baseline demographic and clinical characteristics (Table 2). A chi square test was performed on the ratios for sex and operator. For the continuous variables both a t-test and 95\% confidence intervals were used. There were no cases where there was a statistically significant difference between the groups that were as similar as possible.

The data from 11 patients who failed to complete the study were compared with the data from the 41 patients who completed the main study before treatment using an unpaired t test (Table 3). There were no statistically significant differences between the groups.

For differences between the Southend and Non-Southend groups before treatment a t-test was performed on all cephalometric angles measured, (Table 4). None of the angles showed any statistically significant difference. This was also confirmed by the over-

Table 1. Method error.

\begin{tabular}{|c|c|c|c|}
\hline & W angle & G axis & M axis \\
\hline Mean difference degrees & -0.3 & 0.27 & 0.2 \\
\hline 95\% CI of difference & -0.88 to 0.28 & -0.17 to 0.71 & -0.13 to 0.53 \\
\hline Maximum error degrees & 4.31 & 3.28 & 2.48 \\
\hline
\end{tabular}


Figure 3. CONSORT flow chart.

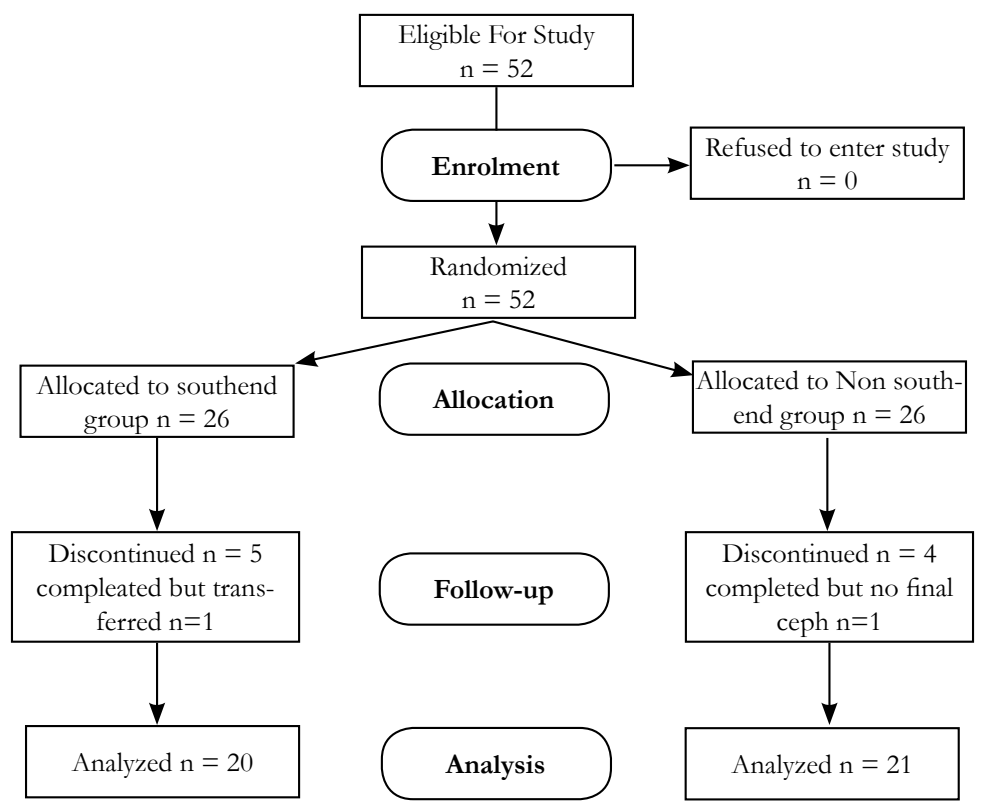

Table 2. Baseline demographic data.

\begin{tabular}{|c|c|c|c|c|c|c|c|c|c|c|}
\hline & \multicolumn{4}{|c|}{ Southend group } & \multicolumn{4}{|c|}{ Non-Southend Group } & $\mathrm{x}^{2}$ & $\mathrm{p}$ \\
\hline Number in the group & \multicolumn{4}{|c|}{13} & \multicolumn{4}{|c|}{13} & & \\
\hline Gender $(\mathrm{M} / \mathrm{F})$ & \multicolumn{4}{|c|}{$4: 9(31: 69) \%$} & \multicolumn{4}{|c|}{$8: 5(62: 38) \%$} & 2.48 & 0.116 \\
\hline Operator(MJT/SRD) & \multicolumn{4}{|c|}{$10: 3(77: 23) \%$} & \multicolumn{4}{|c|}{$8: 5(62: 38) \%$} & 0.72 & 0.400 \\
\hline & Mean & SD & $95 \%$ & CI & Mean & SD & $95 \%$ & CI & $\mathbf{t}$ & $\mathrm{p}$ \\
\hline Age at start(decimal years) & 13.3 & 1.7 & 12.2 & 14.3 & 13.7 & 1.6 & 12.4 & 14.3 & -0.09 & 0.466 \\
\hline $\begin{array}{l}\text { Treatment time with Twin- } \\
\text { blocks (months) }\end{array}$ & 10.7 & 3.3 & 8.7 & 11.9 & 9.8 & 2.4 & 8.3 & 11.2 & 0.82 & 0.210 \\
\hline Overjet at start(mm) & 11.1 & 1.9 & 10.0 & 12.2 & 11.6 & 1.9 & 10.4 & 12.8 & -0.73 & 0.238 \\
\hline
\end{tabular}

Table 3. Comparison of drop out of and completed treatment groups.

\begin{tabular}{|c|c|c|c|c|c|c|c|c|c|c|}
\hline & \multicolumn{3}{|c|}{ Drop outs } & Completed treatment & $\mathbf{x}^{2}$ & p \\
\hline Number in the Group & \multicolumn{3}{|c|}{11} & \multicolumn{3}{c|}{41} & & \\
\hline Gender(M/F) & \multicolumn{3}{|c|}{$7: 4(64: 36) \%$} & \multicolumn{3}{c|}{$19: 22(46: 54) \%$} & 1.04 & 0.308 \\
\hline Operator(MJT/SRD) & \multicolumn{3}{|c|}{$7: 4(64: 36) \%$} & \multicolumn{3}{c|}{$20: 21(49: 51) \%$} & 0.12 & 0.734 \\
\hline Southend & \multicolumn{3}{|c|}{$6: 5(55: 45) \%$} & Mean & SD & $\mathbf{9 5} \%$ & CI & t & p \\
\hline $\begin{array}{c}\text { Measurements at the } \\
\text { start of treatment }\end{array}$ & Mean & SD & $\mathbf{9 5 \%}$ & CI & & & & & & \\
\hline Age(decimal years) & 15.1 & 3.6 & 12.7 & 17.5 & 14.6 & 3.9 & 13.4 & 15.9 & -0.37 & 0.718 \\
\hline Overjet (mm) & 9.7 & 2.1 & 8.3 & 11.1 & 10.9 & 2.1 & 10.3 & 11.7 & 1.74 & 0.101 \\
\hline W angle & 50.5 & 2.3 & 48.9 & 52.0 & 49.2 & 2.8 & 48.3 & 50.1 & -1.32 & 0.155 \\
\hline G-axis & 69.2 & 2.1 & 67.8 & 70.6 & 69.5 & 3.7 & 68.4 & 70.7 & 0.28 & 0.389 \\
\hline M-axis & 44.7 & 2.4 & 43.1 & 46.3 & 44.2 & 2.7 & 43.4 & 45.0 & -0.6 & 0.275 \\
\hline
\end{tabular}

Table 4. Comparison of the groups before treatment.

\begin{tabular}{|c|c|c|c|c|c|c|c|c|c|c|}
\hline & \multicolumn{4}{|c|}{ Southend group } & \multicolumn{4}{|c|}{ Non-Southend group } & \multirow{2}{*}{$\mathbf{t}$} & \multirow{2}{*}{$\mathrm{p}$} \\
\hline PARAMETER & Mean & SD & $95 \%$ & $\mathrm{CI}$ & Mean & SD & $95 \%$ & CI & & \\
\hline W angle & 48.6 & 2.8 & 46.9 & 50.3 & 48.5 & 3.2 & 46.6 & 50.4 & 0.07 & 0.474 \\
\hline G-axis & 69.4 & 3.2 & 67.4 & 71.3 & 68.9 & 3.6 & 66.7 & 71.0 & 0.41 & 0.344 \\
\hline M-axis & 44.5 & 2.2 & 43.1 & 45.8 & 43.4 & 2.1 & 42.1 & 44.7 & 1.26 & 0.110 \\
\hline
\end{tabular}


lap of confidence intervals. The same was true for overjet. Both groups were therefore equivalent before treatment confirming the success of the randomization procedure.

\section{Numbers analysed for each outcome}

The first patient entered the trial in July 2003 and the last patient completed the trial in September 2008. Of the 26 patients allocated to both groups, 20 were analysed in the Southend group and 21 in the Non-Southend group. The trial was ended when the numbers entered reached those required by the power calculation.

\section{Before and after treatment}

The results before and after treatment are shown in Table 5. For $\mathrm{W}$ angle there was a significant increase in both groups with nonoverlap of confidence intervals. This increase was greater for the Southend group.

For G-axis there was no significant difference with overlap of confidence intervals. For M-axis there was no significant difference with overlap of confidence intervals.

\section{Treatment Change}

- The results for treatment change are shown in Table 6.

- For W angle there was a greater increase in the Southend group over the Non-Southend group which was statistically significant with non-overlap of confidence intervals.

- For G-axis there was no statistically significant change with overlap of confidence intervals.

- For M-axis there was no statistically significant change with overlap of confidence intervals.

\section{Harms}

No harm was observed to the patients during the study.

\section{Discussion}

Bhad et al [25] selected patients into Class I, II or IIl groups using Beta angle with one of two criteria based on ANB angle and Witts appraisal. Using receiver operating characteristics curves they showed that patients with Class I skeletal pattern had a W angle between 51 and 56 degrees. A W angle less than 51 degrees indicated Class II and greater than 56 degrees Class III skeletal pattern.

Before treatment the mean W angle was 48.6 degrees for the Southend group and 48.5 degrees for the Non-Southend group with no statistically significant difference between the two (Table 4). These values were close to the means reported for Class II patients by Bhad et al [25] of 48.9 degrees and AI Mashhadany [29] of 49.6 degrees. Both groups were therefore equivalent before treatment confirming the success of the randomization procedure.

After treatment the mean value for the Southend group was 53.9 degrees which was greater than that for the Non-Southend group of 52.2 degrees. The values for both groups were well within the defined range of 51 to 56 degrees for Class I skeletal pattern. The mean value for the Southend group of 53.9 degrees was closer to the mean values for Class I patients reported by Bhad et al [25] of 53.7 degrees and AI Mashhadany [29] of 54.8 degrees.

Thus the W angle was reduced completely to its Class I normative value in the Southend group but less so in the Non-Southend group.

For angle ANB the normal range is from $2.0^{\circ}$ to $3.5^{\circ}$ for males and $2.6^{\circ}$ to $3.0^{\circ}$ for females between 9-20 years [34]. Angle ANB was reduced to $3.9^{\circ}$ in the Southend and $4.5^{\circ}$ in the Non-Southend group [2,3] and so was not completely reduced to Class I values in either group.

Table 5. Comparison of the groups before and after treatment.

\begin{tabular}{|c|c|c|c|c|c|c|c|c|c|c|c|}
\hline & & \multicolumn{4}{|c|}{ Before treatment } & \multicolumn{4}{|c|}{ After treatment } & \multirow{2}{*}{$\mathbf{t}$} & \multirow{2}{*}{$\mathrm{p}$} \\
\hline \multicolumn{2}{|c|}{ PARAMETER GROUP } & Mean & SD & $95 \%$ & $\mathrm{CI}$ & Mean & SD & $95 \%$ & CI & & \\
\hline \multirow[t]{2}{*}{$\mathrm{W}$ angle } & Southend & 48.6 & 2.8 & 46.9 & 50.3 & 53.9 & 3.4 & 51.9 & 56.0 & -4.33 & 0.000 \\
\hline & Non-Southend & 48.5 & 3.2 & 46.6 & 50.4 & 52.2 & 2.7 & 50.6 & 53.8 & -3.20 & 0.001 \\
\hline \multirow[t]{2}{*}{ G-axis } & Southend & 69.4 & 3.2 & 67.4 & 71.3 & 69.2 & 3.5 & 67.0 & 71.3 & 0.18 & 0.43 \\
\hline & Non-Southend & 68.9 & 3.6 & 66.7 & 71.0 & 68.9 & 3.0 & 67.1 & 70.7 & -0.06 & 0.476 \\
\hline \multirow[t]{2}{*}{ M-axis } & Southend & 44.5 & 2.2 & 43.1 & 45.8 & 44.7 & 2.2 & 43.4 & 46 & -0.27 & 0.395 \\
\hline & Non-Southend & 43.4 & 2.1 & 42.1 & 44.7 & 43.3 & 2.1 & 42.0 & 44.6 & 0.09 & 0.464 \\
\hline
\end{tabular}

Table 6. Treatment Change.

\begin{tabular}{|c|c|c|c|c|c|c|c|c|c|c|}
\hline & \multicolumn{4}{|c|}{ Southend group } & \multicolumn{4}{|c|}{ Non-Southend group } & \multirow[b]{2}{*}{$\mathbf{t}$} & \multirow{2}{*}{$\mathrm{p}$} \\
\hline PARAMETER & Mean & SD & $95 \%$ & CI & Mean & SD & $95 \%$ & CI & & \\
\hline $\mathrm{W}$ angle & 5.3 & 1.8 & 4.2 & 6.4 & 2.9 & 1.9 & 1.7 & 4.0 & 3.22 & 0.001 \\
\hline G-axis & -0.2 & 0.8 & -0.7 & 0.3 & 0 & 1.4 & -0.8 & 0.9 & -0.67 & 0.255 \\
\hline M-axis & 0.2 & 1.2 & -0.5 & 1.0 & 0.1 & 1.1 & -0.8 & 0.6 & 0.67 & 0.256 \\
\hline
\end{tabular}


When comparing the results before and after treatment for W angle (Table 5), there was a highly significant difference in both groups which was greater in the Southend group reflecting the change from Skeletal II to Skeletal I pattern during treatment. A similar difference was observed for angle ANB [3].

For treatment change the $\mathrm{W}$ angle increased by 5.3 degrees in the Southend group compared with 2.9 degrees in the Non-Southend group, the difference being statistically highly significant (Table 6). For angle ANB there was a -3.5 degree reduction in the Southend group and -2.6 degree reduction in the Non-Southend group. Whilst the difference was statistically significant, it was at a lower level of probability than for $\mathrm{W}$ angle $[2,3]$.

The $\mathrm{W}$ angle proved to be a more sensitive measure of skeletal change than angle ANB. Not only was the treatment change greater for W angle than angle ANB but there was a 2.4 degree difference in treatment change between the Southend and NonSouthend groups compared to 0.9 degrees for angle ANB. Thus the elimination of confounding factors that influence angle ANB had a noticeable effect on $\mathrm{W}$ angle as a measure of skeletal pattern. This resulted in a greater differentiation of the treatment response not only within but also between the Southend and NonSouthend groups.

\section{Growth direction and vertical changes}

Both $\mathrm{M}$ axis and $\mathrm{G}$ axis are stable during normal growth [27, 28] hence any changes were due to the effects of treatment. The $\mathrm{M}$ axis showed no significant change with treatment (Table 6). The $G$ axis also showed no significant change with treatment (Table 6). Thus the Twin-block appliance did not alter the overall growth direction which was in agreement with the work of Lau et al [35] who found that the Twin-block appliance did not induce any maxillary or mandibular internal rotations.

\section{Limitations}

The main limitation of $\mathrm{W}$ angle as a method is that it does not distinguish whether the skeletal change occurs in the maxilla or mandible.

The question arises can the differences in outcome be attributed to the effects of treatment rather than differences in the pre-treatment characteristics of the patient groups. This would depend on the elimination of bias which systematically distorts the results. Bias occurs if all factors other than the intervention under test are not equal. Selection or allocation bias is overcome by random allocation using sealed envelopes to achieve concealment and avoid bias in the creation of the comparison groups. Statistical testing failed to show any pre-treatment differences between the Southend and Non-Southend groups for either cephalometric or demographic factors confirming the success of the randomization procedure.

The 11 patients who defaulted on treatment may differ from the 41 patients who completed introducing attrition bias. When the default treatment group was compared with the completed treatment group, there were no statistically significant differences [2]. There was however, a small but non-significant trend to there being more males and less severe skeletal discrepancy in the default treatment group.
Assessment bias is reduced by blinding and training of operators and standardization of techniques. Operators could not be blinded to appliance design once selected, however the Southend clasp was passive and required no adjustment, making the management of both designs of appliance identical. If the operator were neutral towards the intervention, it is unlikely that lack of masking will bias the trial results [36]. Also the labial bows were entirely passive; their effect being the same in both groups, hence any differences were due to the presence or absence of the Southend clasps. In fact, a recent prospective randomized trial has shown that the presence or absence of a labial bow had no effect on maxillary incisor retraction or skeletal change [36]. In addition the tracer was blinded to the group allocated to each cephalometric radiograph.

Age could act as a confounding factor in the investigation. That is age could affect skeletal response as well as appliance design. Given the age range of the study (9-17 years), the skeletal response could vary with age; however, there was no correlation between age and increase in $\mathrm{W}$ angle (Pearson correlation coefficient $\mathrm{r}=-0.13$ ) hence age could be excluded as a confounding factor. However, there was a correlation between $\mathrm{W}$ angle and treatment time $(r=0.33)$ indicating the rate of growth but not the amount of growth was influenced by age.

The interaction between change in incisor angulation and remodelling of points A and B is another confounding factor. Retroclination of the upper incisors will tend to remodel point $A$ forwards and proclination of the lower incisors will tend to remodel point $\mathrm{B}$ backwards. The effect of this will be to increase angle ANB which at the same time is being reduced by the skeletal response to the Twin-block appliance. Hence there is a tendency to lessen the reduction in angle ANB during treatment. This appears to happen relative to $\mathrm{W}$ angle which is uninfluenced by changes in incisor angulation. The result is that $\mathrm{W}$ angle has a greater range between before and after treatment $\left(5.3^{\circ}\right.$ Southend, $2.9^{\circ}$ NonSouthend) compared to angle ANB ( $-3.5^{\circ}$ Southend, $-2.6^{\circ}$ NonSouthend). The correlation between $\mathrm{W}$ angle and angle ANB is greater in the Southend group $(\mathrm{r}=0.76)$ where there is less incisor movement than the Non-Southend group $(r=0.31)$ where there is significantly greater movement.

Trenouth and Mew [1] found that in the group of Class II division 1 patients treated by upper incisor retraction with a removable appliance angle ANB increased by $1^{\circ}$ presumably due to forward movement of the upper incisor apex and remodelling of point $A$ forwards. This also explains why angle ANB is not reduced to its normative Class I value unlike W angle.

The present study was the first prospective randomized controlled trial on the effect of clasping on control of upper and lower incisor angulation in Twin-block appliance treatment. This represents a higher level of evidence than previous retrospective studies [38, 39]. A prospective, longitudinal randomized controlled trial allows causal association between intervention and outcome that is the presence of a Southend clasp and control of incisor angulation and skeletal response.

\section{Generalizability}

W angle can be used as an alternative to angle ANB in the assessment of sagittal discrepancy. The main justification for the use of $\mathrm{W}$ angle over angle ANB is that it is not influenced by 
growth and change in incisor angulation. Both points $A$ and $B$ are influenced by movement of the incisor root apices which result in remodelling of the alveolar bone because they are deep alveolar points. Points $M$ and $G$ are centroid in nature being dependent on three surfaces and not influenced by changes in incisor angulation. They are in fact true skeletal points. Although angle ANB remains the traditional and most common method for assessing sagittal discrepancy its use is compromised where treatment results in changes in incisor angulation. In such a situation $\mathrm{W}$ angle becomes the method of choice. This has been demonstrated in the present study of Twin-block appliance outcome where both skeletal and incisor angulation changes occur simultaneously during treatment.

\section{Acknowledgement}

Thanks to Karen Pool for word processing the manuscript and collating the patient records.

Registration: www.controlled-trials.com/ISRCTN 45965219

Protocol: The protocol was established but not published before trial commencement.

Funding: No funding or conflict of interest is declared.

\section{Conclusions}

The $\mathrm{W}$ angle proved to be a more valid measure of skeletal change than angle ANB. This was because:

1. $M$ and $G$ are true skeletal points rather than $A$ and $B$ which are deep alveolar points.

2. W angle is not influenced by confounding factors, whereas angle ANB is effected by growth and changes in incisor angulation. The greatest change during treatment was that of upper and lower incisor angulation, which influenced angle ANB but not $\mathrm{W}$ angle.

3. Points $M$ and $G$ have been shown to be stable during growth and are unaffected by treatment.

The greater validity of $\mathrm{W}$ angle as a measure of skeletal change over angle ANB is supported by three findings:

1. W angle demonstrated a greater range and clearer distinction between before and after treatment $\left(5.3^{\circ}\right.$ Southend, $2.9^{\circ}$ Non-Southend) than angle ANB (-3.5 Southend, $-2.6^{\circ}$ NonSouthend).

2. W angle showed a greater difference between the Southend and Non-Southend groups $\left(2.4^{\circ}\right)$ than angle ANB $\left(0.9^{\circ}\right)$.

3. There was total reduction to Class I normative values for W angle (54.4 ${ }^{\circ}$ Southend, $52.2^{\circ}$ Non-Southend, norm 51-56 $)$, but not for angle ANB (3.9 $9^{\circ}$ Southend, $4.5^{\circ}$ Non-Southend, norm $2.0-3.5^{\circ}$ ).

As a consequence, W angle would be the method of choice for evaluating the outcome of functional appliance therapy. It would also have a similar application in the evaluation of orthognathic surgery outcome.

\section{References}

[1]. Trenouth MJ, Mew J (1997) A comparative cephalometric evaluation of four different methods of orthodontic treatment. Cranio View 6: 16-24.
[2]. Trenouth MJ, Desmond S (2012) A randomized clinical trial of two alternative designs of Twin-block appliance. J Orthod 39(1): 17-24.

[3]. Trenouth MJ, Desmond S (2013) The influence of clasp design on Twinblock appliance outcome-a prospective randomized, controlled clinical trial. Cranio View 22: 18-34.

[4]. Harradine NW, Gale D (2000) The effects of torque control spurs in Twinblock appliances. Clin Orthod Res 3(4): 202-209.

[5]. Parkin NA, McKeown HF, Sandler PJ (2001) Comparison of 2 modifications of the Twin-block appliance in matched Class II samples. Am J Orthod Dentofacial Orthop 119(6): 572-577.

[6]. Riedel RA (1952) The relation of maxillary structures to cranium in malocclusion and in normal occlusion. Angle Orthod 22(3): 142-145.

[7]. Jacobson A (1975) The "Wits" appraisal of jaw disharmony. Am J Orthod 67(2): 125-138.

[8]. Jacobson A (1976) Application of the "Wits" appraisal. Am J Orthod 70(2): 179-189.

[9]. Hussels W, Nanda RS (1984) Analysis of factors affecting angle ANB. Am J Orthod 85(5): 411-423.

[10]. Hussels W, Nanda RS (1987) Clinical application of a method to correct angle ANB for geometric effects. Am J Orthod Dentofacial Orthop 92(6): 506-510.

[11]. Freeman RS (1981) Adjusting A-N-B angles to reflect the effect of maxillary position. Angle Orthod 51(2): 162-171.

[12]. Binder RE (1979) The geometry of cephalometrics. J Clin Orthod 13(4): 258-263.

[13]. Arvysts MG (1990) Non-extraction treatment of severe Class II, division 2 malocclusions. Am J Orthod Dentofacial Orthop 97(6): 510-521.

[14]. Erverdi N (1991) A cephalometric study of changes in point A under the influence of upper incisor inclinations. J Nihon Univ Sch Dent 33(3): 160 165.

[15]. Lund DI, Sandler PJ (1998) The effects of Twin-blocks: a prospective controlled study. Am J Orthod Dentofacial Orthop 113(1): 104-110.

[16]. Richardson M (1982) Measurement of dental base relationship. Eur J Orthod 4(4): 251-256.

[17]. Frank S (1983) The occlusal plane reliability of its cephalometric location and its changes with growth. University of Oklahoma, Oklahoma City. $1-158$.

[18]. Sherman SL, Woods M, Nanda RS, Currier GF (1998) The longitudinal effects of growth on the "Wits" appraisal. Am J Orthod Dentofacial Orthop 93(5): 429-436.

[19]. Rushton R, Cohen AM, Linney AD (1991) The relationship and reproducibility of angle ANB and the "Wits" appraisal. Br J Orthod 18(3): 225-231.

[20]. Haynes S, Chau M (1995) The reproducibility and repeatability of the Wits analysis. Am J Orthod Dentofacial Orthop 107(6): 640-647.

[21]. Baik CY, Ververidou M (2004) A new approach of assessing sagittal discrepancies: The Beta angle. Am J Orthod Dentofacial Orthop 126(1): 100-105.

[22]. Neela PK, Mascarenhas R, Husain A (2009) A new sagittal dysplasia indicator: The Yen angle. World J Orthod 10(2): 147-151.

[23]. Shetty S, Husain A, Majitha P, Uddin S (2013) Yen-linear: a sagittal cephalometric parameter. J World Fed Orthod 2(2): e57-e60.

[24]. Kumar S, Valiathan A, Gautam P, Chakravarthy K, Jaysaswal P (2012) An evaluation of the $\mathrm{Pi}$ analysis in the assessment of anteroposterior jaw relationship. J Orthod 39(4): 262-269.

[25]. Bhad WA, Nayak S, Doshi UH (2013) A new approach of assessing sagittal dysplasia: the W angle. Eur J Orthod 35(1): 66-70.

[26]. Nanda RS, Merrill RM (1994) Cephalometric assessment of sagittal relationship between maxilla and mandible. Am J Orthod Dentofacial Orthop 105(4): 328-344.

[27]. Braun S, Rudman RT, Murdoch HJ, Hicken S, Kittleson R, et al. (1999) Caxis: a growth vector for the maxilla. Angle Orthod 69(6): 539-542.

[28]. Braun S, Kittleson R, Kim K (2004) The G-axis: a growth vector for the mandible. Angle Orthod 74(3): 328-331.

[29]. Al-Mashhadany SM (2012) The relation between W angle and other methods used to assess the sagittal jaw relationship. J Bagh Coll Dentistry 24(2): 144-149.

[30]. Trenouth MJ (1989) A functional appliance system for the correction of Class II relationships. Br J Orthod 16(3): 169-176.

[31]. O’Brien K, Wright J, Conboy F, Sanjie Y, Mandall N, et al (2003) Effectiveness of treatment for Class II malocclusion with the Herbst or Twin-block appliances: a randomized controlled trial. Am J Orthod Dentofacial Orthop 124(2): 128-137.

[32]. Banks P, Wright J, O’Brien K (2004) Incremental versus maximum bite advancement during Twin-block therapy: a randomized controlled clinical trial. Am J Orthod Dentofacial Orthop 126(5): 583-588.

[33]. Bland JM, Altman DG (1996) Statistical notes: measurement error. Brit Med J 313(7059): 744.

[34]. Bhatia SN, Leighton BC (1993) A manual of facial growth. A computer analysis of longitudinal cephalometric growth data. Oxford: Oxford Uni- 
versity Press.

[35]. Lau EY, Sampson WJ, Townsend GC, Hughes T (2009) An evaluation of maxillary and mandibular rotational responses with the Clark Twin-block appliance. Aust Orthod J 25(1): 48-58.

[36]. Pandis N (2012) Blinding or masking. Am J Orthod Dentofacial Orthop 141(3): 389-390.

[37]. Yaqoob O, DiBiase AT, Fleming PS, Cobourne MT (2012) Use of the Clark Twin-block functional appliance with and without an upper labial bow: a randomized controlled trial. Angle Orthod 82(2): 363-369.

[38]. Zuccati G, Clauser C, Giorgetti R (2009) Randomized clinical trials in orthodontics: Reality, dream or nightmare? Am J Orthod Dentofacial Orthop 136(5): 634-637.

[39]. Pandis N (2011) Sources of bias in clinical trials. Am J Orthod Dentofacial Orthop 140(4): 595-596.
Special Issue on

"Long-term effects of orthodontic treatment"

Theme Edited by:

Saeed M Banabilh, Qassim University, Saudi Arabia. E-Mail: banabilh23@gmail.com

Yanqi Yang, University of HongKong, Hong Kong. E-Mail: yangyanq@hku.hk 